\title{
Kandungan Vitamin C dari Ekstrak Buah Ara (Ficus carica L.) dan Markisa Hutan (Passiflora foetida L.)
}

\author{
James Ngginak $^{1, *}$, Anggreini Dian Naomi Rupidara ${ }^{1}$, Yanti Daud ${ }^{1}$ \\ ${ }^{1} J u r u s a n$ Pendidikan Biologi, Fakultas Keguruan dan Ilmu Pendidikan, Universitas Kristen Artha Wacana, \\ Oesapa, Kupang (NTT) 85228 \\ *email korespondensi: james ngginak@yahoo.com
}

Received : 7 Mei 2019 ; Revised : 17 Mei 2019; Accepted : 28 Agustus 2019; Published: 8 September 2019

\section{ABSTRAK}

Vitamin C merupakan salah satu senyawa antioksidan yang efektif dalam menangkal radikal bebas. Komponen ini umumnya terkandung dalam buah-buahan dan sayuran. Buah-buahan yang tumbuh liar seperti buah ara (Ficus carica L.) dan buah markisa hutan (Passiflora feotida L.) juga mengandung vitamin C. Tujuan dari penelitian ini yaitu untuk mengetahui kandungan vitamin C pada buah ara dan markisa hutan yang tumbuh di Kecamatan Taebenu Kabupaten Kupang. Metode atau instrumen yang digunakan dalam penelitian ini yaitu metode lodometri dan metode Spektrofotometri UV-Vis. Hasil penelitian menggunakan metode iodometri menunjukkan bahwa pada buah ara mengandung 4,13 $\mathrm{mg}$ vitamin C dan buah markisa hutan mengandung 5,16 $\mathrm{mg}$ vitamin $\mathrm{C}$. Hasil analisis menggunakan Spektrofotometer UV-VIS diperoleh kandungan vitamin C pada buah ara 1,244 mg/L serta kandungan vitamin C pada buah markisa hutan 1,904 mg/L. Dengan demikian, dapat dikatakan bahwa buah ara dan markisa hutan merupakan dua jenis buah liar yang dapat dimanfaatkan sebagai bahan makanan untuk memenuhi asupan vitamin C bagi manusia. Saran bagi peneliti selanjutnya untuk melakukan uji antioksidan dan uji bakteri dari kedua jenis sampel.

Kata-kata kunci: buah ara; buah markisa hutan; iodometri; spektrofotometri; vitamin C

\section{PENDAHULUAN}

Nusa Tenggara Timur (NTT) merupakan salah satu provinsi yang memiliki tingkat biodiversitas tumbuhan yang baik. Tumbuhan yang tumbuh alami atau liar mempunyai kontribusi besar dalam bidang pangan bahkan turut serta dalam menyokong ekonomi masyarakat. Keanekaragaman hayati yang disediakan oleh alam adalah fondasi bagi kehidupan masyarakat NTT. Jenis tumbuhan liar yang memiliki kontribusi ekonomis dalam kehidupan masyarakat NTT seperti asam, kesambi, dan lontar. Jenis tumbuhan ini dapat kita temukan di Kabupaten Kupang dan beberapa daerah lain di pulau Timor. Informasi kebaruan dari kajian ini adalah bahwa tumbuhan yang tumbuh secara alami atau liar sebenarnya memiliki potensi pangan dan kesehatan bagi manusia.

Beberapa tumbuhan yang tumbuh secara alami dan memiliki fungsi pangan yaitu ara dan markisa hutan. Buah ara dan markisa hutan dimanfaatkan oleh masyarakat sebagai makanan tambahan. Pohon ara dan markisa hutan adalah dua jenis tumbuhan tropis yang dapat kita temukan di lingkungan sekitar. Ciri-ciri dari pohon ara yaitu memiliki batang yang kokoh dan tergolong dalam tumbuhan dikotil serta memiliki buah yang rasanya manis jika sudah mencapai tingkat kematangan yang maksimal. Sedangkan, markisa hutan merupakan tumbuhan monokotil yang juga memiliki buah yang dapat dikonsumsi jika sudah matang. Cita rasa buah yang manis dan segar bila sudah matang menjadi pilihan untuk dikonsumsi. Selain rasa buah yang menjadi daya pikat, buah ara, dan markisa hutan juga memiliki kandungan senyawa yang penting untuk kesehatan tubuh manusia. Menurut Tahir dkk. (2017), kandungan senyawa aktif pada kedua jenis buah dapat digunakan untuk mengobati penyakit seperti penyakit jantung, kanker, serta gangguan pencernaan. Fenol, flavonoid, tanin, alkaloid, dan saponin adalah sebagian dari senyawa aktif yang terkandung dalam buahbuahan (Tahir dkk., 2017). Senyawa aktif yang ditemukan pada buah buah-buahan umumnya mampu berperan sebagai antioksidan (Karinda dkk., 2013). Selain polifenol, vitamin C yang terkandung dalam buahbuahan dan sayuran merupakan sumber antioksidan yang baik untuk tubuh.

Vitamin $C$ adalah salah satu senyawa kompleks yang terdapat dalam buah dan sayuran yang memiliki sifat larut air. Menurut Tahir dkk. (2017), vitamin C merupakan suatu senyawa atau zat gizi yang dibutuhkan oleh tubuh dengan prekusornya adalah karbohidrat. Vitamin $\mathrm{C}$ dikenal juga dengan nama asam askorbat. 
Dalam tubuh manusia senyawa ini berfungsi sebagai katalis dalam reaksi kimia. Oleh karena itu, jika jenis katalis ini tidak terdapat dalam tubuh maka fungsi normal tubuh akan terganggu (Setyawati, 2014). Tubuh manusia tidak dapat menghasilkan vitamin $\mathrm{C}$ sehingga kebutuhan vitamin $\mathrm{C}$ dalam tubuh dipenuhi melalui asupan bahan makanan. Bahan makanan seperti sayuran dan buah-buahan segar adalah sumber vitamin $C$ yang baik. Vitamin $\mathrm{C}$ memiliki sifat mudah larut dalam air dan mudah teroksidasi. Asam askorbat atau vitamin C dalam buah-buahan dan sayuran akan rusak atau berkurang akibat proses oksidasi berupa paparan udara, pemasakan dan pengirisan, serta penyimpanan yang tidak tepat. Salah satu bentuk tindakan agar kandungan vitamin $C$ pada sayuran dan buah-buahan tetap terjaga yaitu proses pengemasan buah dan sayuran pada suhu rendah (di lemari es). Menurut Aina \& Suprayogi (2011), manfaat vitamin C bagi tubuh yaitu sebagai antioksidan, sintesis kolagen, dan anti kanker. Kebutuhan vitamin $C$ oleh setiap tubuh berbeda, hal ini tergantung pada usia, jenis kelamin, sifat metabolisme, dan penyakit tertentu. Orang dewasa diajurkan konsumsi 100- 150 mg vitamin C (Badriyah \& Manggara, 2015).

Informasi mengenai kandungan vitamin $\mathrm{C}$ pada buah markisa hutan dan buah ara diharapkan dapat dimaksimalkan oleh masyarakat sebagai bahan pangan tambahan dan sebagai informasi penting dalam pengembangan usaha masyarakat. Bertolak dari uraian tersebut maka perlu dilakukan penelitian tentang kandungan vitamin C pada ekstrak buah ara (Ficus carica L.) dan markisa hutan (Passiflora foetida L.).

\section{METODE PENELITIAN}

\section{Alat dan Bahan}

Alat yang digunakan yaitu blender (Advance), batang pengaduk, corong pisah, mortar, Erlenmeyer (Pyrex $250 \mathrm{~mL}$ ), gelas kimia (Pyrex $500 \mathrm{~mL}$ ), gelas ukur, timbangan analitik, alat maserasi, kuvet, pipet tetes, kertas saring Whatmann No 1, spektrofotometer UV-Vis (Shimadzu BioSpec mini UV-Vis), dan magnetic stirrer. Bahan yang digunakan adalah daging buah ara dan markisa masing-masing $25 \mathrm{~g}$, vitamin C $25 \mathrm{mg}$ (food grade), lodium 0,01 N (teknis), aquades bebas $\mathrm{CO}_{2}$ atau aquabidest, etanol 96\% (Merck, grade PA), Natrium tiosulfat (Merck, grade PA), asam asetat $10 \%$ (teknis), dan $\mathrm{H}_{2} \mathrm{SO}_{4} 5 \%$ (teknis).

Analisis vitamin $\mathrm{C}$ pada daging buah ara dan markisa hutan menggunakan metode lodometri (titrasi) dan spektrofotometri. Perubahan warna yang terjadi pada pereaksi iod menjadi indikator bahwa pada sampel terkandung vitamin C. Analisis vitamin C menggunakan spektrofotometer UV-Vis menunjukkan bahwa vitamin C pada sampel terbaca pada panjang gelombang $620 \mathrm{~nm}$.

\section{Prosedur Kerja}

Penentuan kadar vitamin C dalam sampel menggunakan metode lodometri (titrasi) (El-Ishaq \& Obirinakem, 2015) dimodifikasi. Sediakan $10 \mathrm{~g}$ sampel halus (daging buah) masing-masing dari buah ara dan markisa hutan pada labu $100 \mathrm{~mL}$ lalu ditambahkan $100 \mathrm{~mL}$ air hingga tanda batas. Tambahkan 5 tetes indikator amilum, lalu lakukan titrasi dengan iodium $\left(\mathrm{I}_{2}\right) 0,01 \mathrm{~N}$ sampai warna biru. Kandungan vitamin $\mathrm{C}$ dapat dihitung dengan rumus:

$$
\text { Kadar vit C }(\mathrm{mg} / 100 \mathrm{~g})=\frac{\left(\mathrm{Vol} \mathrm{I}_{2} \times 0,88 \times \mathrm{Fp}\right) \times 100}{\mathrm{~W} \text { sampel }(\mathrm{g})}
$$

Keterangan:

$\mathrm{VI}_{2} \quad$ : Volume iodium $(\mathrm{mL})$

0,88 : 0,88 $\mathrm{mg}$ Vitamin $\mathrm{C}$ setara dengan $1 \mathrm{~mL}$ larutan $\mathrm{I}_{2} 0,01 \mathrm{~N}$

$\mathrm{Fp} \quad$ : faktor pengenceran

Ws : Berat sampel (g)

Analisis vitamin C menggunakan metode spektrofotometri diawali dengan penyiapan dan pembuatan larutan standard. Ditimbang dengan teliti $25 \mathrm{mg}$ vitamin $\mathrm{C}$ standard kemudian dimasukkan ke dalam labu ukur $25 \mathrm{~mL}$ lalu dilarutkan dengan asam oksalat 0,4\% hingga $25 \mathrm{~mL}(0,2 \mathrm{ppm})$. Tahap berikutnya adalah penentuan panjang gelombang maksimum untuk standard. Dipipet $0,8 \mathrm{~mL}$ larutan vitamin $\mathrm{C}(0,2$ ppm), lalu dimasukkan ke dalam labu ukur $10 \mathrm{~mL}$ (konsentrasi $80 \mathrm{ppm}$ ), lalu ditambahkan $\mathrm{H}_{2} \mathrm{SO}_{4} 5 \%$ sebanyak $4 \mathrm{~mL}$, kemudian ditambahkan (ammonium molibdat $5 \%$ jika memakai pereaksi) sampai batas tanda tera dan dihomogenkan. Campuran larutan ini diinkubasi selama 30 menit, lalu diukur serapannya dengan spektrofotometer UV-Vis pada rentang panjang gelombang $500-750 \mathrm{~nm}$. 


\section{Pembuatan kurva standard}

Larutan vitamin C 0,2 ppm dipipet sebanyak 5 kali yaitu 0,$1 ; 0,2 ; 0,3 ; 0,4 ; 0,5 \mathrm{~mL}$. Masing-masing dimasukkan ke dalam labu ukur $10 \mathrm{~mL}$, kemudian ditambahkan $\mathrm{H}_{2} \mathrm{SO}_{4} 5 \%$ sebanyak $4 \mathrm{~mL}$ (tambahkan ammonium molibdat 5\% sampai batas tanda, jika menggunakan pereaksi) dikocok dan dihomogenkan (diperoleh konsentrasi $0,0,1 ; 0,18 ; 0,38 ; 0,53 ; 0,66 \mathrm{ppm}$ ), kemudian diinkubasi selama 30 menit. Seri konsentrasi selanjutnya diukur serapannya dengan spektrofotometri UV-Vis pada panjang gelombang 620 $\mathrm{nm}$. Selanjutnya dibuat kurva kalibrasi antara konsentrasi dan absorbansi untuk mendapatkan persamaan garis atau regresi linear. Pengukuran kadar vitamin C dilakukan dengan menimbang masing-masing $10 \mathrm{mg}$ ekstrak etanol (bisa menggunakan air) sampel ke dalam $25 \mathrm{~mL}$ labu ukur. Sampel dilarutkan dengan etanol $96 \%$ sampai batas tanda tera. Dipipet $1 \mathrm{~mL}$ dari larutan ekstrak sampel kemudian dimasukkan ke dalam labu ukur $10 \mathrm{~mL}$ dan ditambahkan $4 \mathrm{~mL} \mathrm{H}_{2} \mathrm{SO}_{4}$ \%, lalu dicukupkan volumenya hingga batas tanda tera dengan (ammonium molibdat 5\% jika menggunakan pereaksi), dikocok hingga homogeni lalu diinkubasi 30 menit kemudian diukur serapannya pada panjang gelombang maksimum yang diperoleh(620 nm)(Tahir dkk., 2017).

\section{HASIL DAN PEMBAHASAN}

\section{Penentuan Kandungan Vitamin C Pada Daging Buah Ara (Ficus carica L.) dan Markisa Hutan (Passiflora foetida L.) dengan Metode lodometri (Titrasi)}

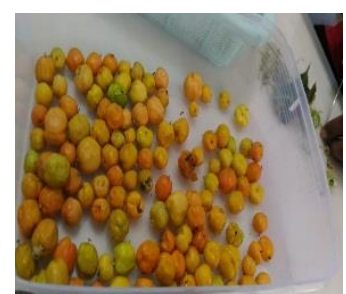

(a)

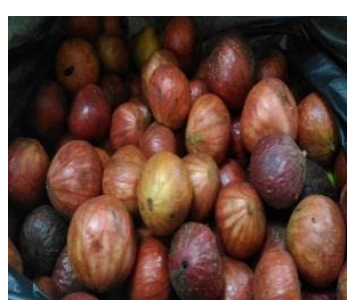

(b)

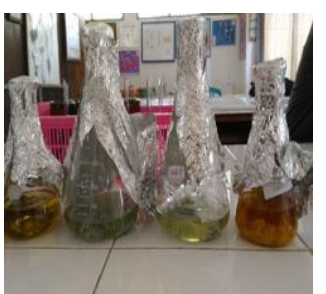

(c)

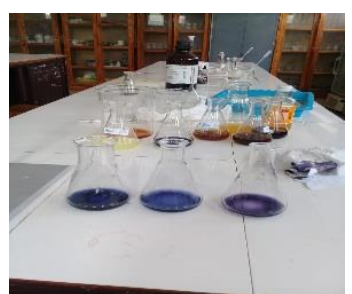

(d)

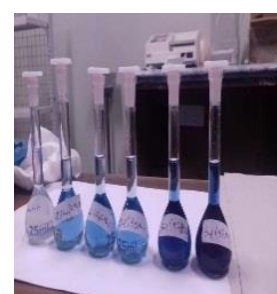

(e)

Gambar 1. Sampel: a) buah Ara (Ficus carica L.); b) buah Markisa hutan (Passiflora foetida L.); c), d) dan e). proses titrasi.

Secara kualitatif penentuan kandungan vitamin C pada daging buah ara (Ficus carica L.) dan markisa hutan (Passiflora foetida L.) menggunakan metode lodometri dapat dilihat pada Tabel 1 berikut:

Tabel 1. Hasil analisis kualitatif vitamin C pada daging buah ara dan markisa hutan

\begin{tabular}{lcc}
\hline Sampel & Pereaksi & Pustaka \\
\hline Daging buah Ara & P1 & Positif $(+)$ \\
Daging buah Markisa hutan & P1 & Positif $(+)$ \\
\hline
\end{tabular}

Keterangan P1 : pereaksi iod

Secara kuantitatif kandungan vitamin C pada daging buah ara (Ficus carica L.) dan markisa hutan (Passiflora foetida L.) menggunakan metode lodometri dapat dilihat pada Tabel 2 berikut:

Tabel 2. Hasil analisis kuantitatif vitamin $C$ pada daging buah ara dan markisa hutan

\begin{tabular}{llll}
\hline Sampel & Volume sampel $(\mathbf{m L})$ & Rata-rata Vol $\mathbf{I}_{\mathbf{2}}(\mathbf{m L})$ & Kadar Vitamin C(mg) \\
\hline Daging buah Ara & 10 & 0,47 & 4,13 \\
Daging buah Markisa & 10 & 0,57 & 5,16 \\
\hline
\end{tabular}

Pembuktian vitamin C secara kualitatif dapat dilakukan dengan menggunakan metode lodometri karena larutan ini mampu mereduksi vitamin C. Vitamin C merupakan zat pereduksi yang kuat dan secara sederhana dapat dititrasi dengan larutan baku iodium sebagai oksidator (Mulyani, 2018). Dengan demikian maka kandungan vitamin $\mathrm{C}$ dalam buah ara dan markisa dapat ditentukan dengan metode lodometri.

Titrasi lodometri adalah sebuah metode yang berdasarkan reaksi redoks dengan mengukur jumlah iodin yang tersisa dari hasil reaksi antara vitamin C dengan reaktan (Damayanti \& Kurniawati, 2017). Amilum yang digunakan sebagai indikator akan ditambahkan pada saat mendekati fase akhir proses titrasi. Titrasi menggunakan iodin bertujuan untuk mereduksi senyawa-senyawa kuat seperti vitamin C. Hasil uji titrasi dengan larutan iodin diberikan hingga warna larutan berwarna biru. Warna biru yang terbentuk sebagai pertanda proses tritrasi telah mencapai titik akhir. Dalam pemberian larutan untuk mencapai titik akhir pada sampel buah ara dibutuhkan $0,47 \mathrm{~mL}$ larutan lodium sedangkan sampel buah markisa dibutuhkan larutan 
iodin sejumlah $0,57 \mathrm{~mL}$. Setelah dilakukan perhitungan kadar vitamin C maka diperoleh kadar vitamin C pada sampel buah ara adalah 4,41 mg dan kadar vitamin C pada buah markisa hutan adalah 5,16 mg.

Vitamin $C$ adalah salah satu senyawa yang mudah teroksidasi karena mengandung gugus fungsi hidroksi yang sangat reaktif. Dengan adanya oksidator gugus hidroksi, vitamin $\mathrm{C}$ akan teroksidasi menjadi gugus karbonil. Proses oksidasi akan terhambat jika vitamin $\mathrm{C}$ berada dalam kondisi sangat asam atau pada suhu rendah. Vitamin $\mathrm{C}$ sangat dibutuhkan oleh tubuh namun diperlukan dalam jumlah yang sedikit. Tubuh tidak dapat menghasilkan vitamin $\mathrm{C}$, oleh karena itu pemenuhan vitamin $\mathrm{C}$ oleh tubuh diperoleh melalui makanan. Kebutuhan vitamin C setiap tubuh berbeda tergantung pada usia dan metabolisme (Badriyah \& Manggara, 2015).

\section{Penentuan Kandungan Vitamin C Pada Daging Buah Ara (Ficus carica L.) dan Markisa Hutan (Passiflora foetida L.) dengan Metode Spektrofotometri \\ Pembuktian vitamin C pada daging buah ara (Ficus carica L.) dan markisa hutan (Passiflora foetida L.) menggunakan metode spektrofotometri dapat dilihat pada Gambar 2. Berdasarkan data hasil pengamatan diperoleh panjang gelombang maksimum $620 \mathrm{~nm}$ dengan nilai absorbansi 0,54.}

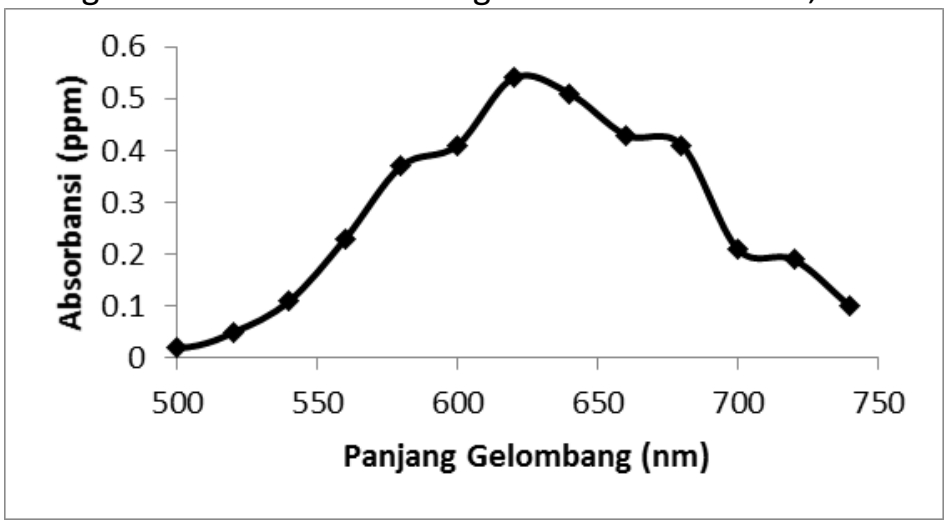

Gambar 2. Panjang gelombang serapan vitamin C standard

\section{Pembuatan kurva kalibrasi}

Kurva kalibrasi untuk larutan standard dengan konsentrasi 0,2 ppm diperoleh deret konsentrasi 0; 0,$1 ; 0,2 ; 0,4 ; 0,6 ;$ dan 0,8 ppm. Hasil kurva kalibrasi vitamin $C$ standard dapat dilihat pada Gambar 3.

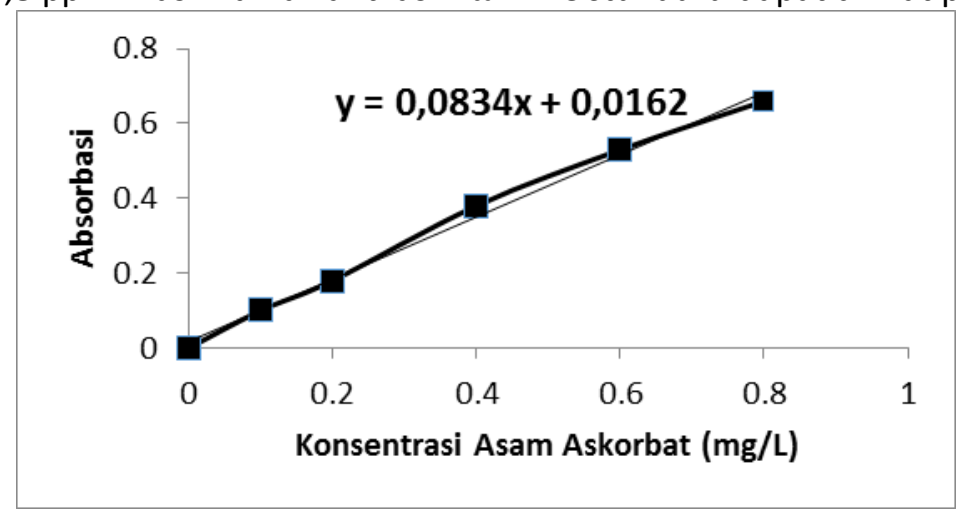

Gambar 3. Kurva kalibrasi vitamin C standard

Hasil analisis menggunakan metode spektrofotometri diperoleh konsentasi vitamin $C$ pada daging buah Ara (Ficus carica L.) dan Markisa hutan (Passiflora foetida L.) dapat dilihat pada Tabel 3 berikut:

Tabel 3. Hasil analisis kuantitatif vitamin $\mathrm{C}$ pada daging buah ara dan markisa hutan

\begin{tabular}{lcc}
\hline \multicolumn{1}{c}{ Variabel } & Serapan (A) & Kadar Vitamin C (mg/L) \\
\hline Daging buah Ara (A) & 0,128 & 1,244 \\
Daging buah Markisa (M) & 0,175 & 1,904 \\
\hline
\end{tabular}

$$
\begin{array}{ll}
\text { Keterangan: } & A=\text { buah ara } \\
& M=\text { buah markisa hutan }
\end{array}
$$

Analisis kadar vitamin $C$ dengan mengguakan dalam sampel ditentukan dengan menggunakan persamaan : $\mathrm{Y}=V \frac{\mathrm{X}}{\mathrm{M}}$ (Setiawan \& Made, 2014) sehingga berdasarkan perhitungan tersebut diperoleh kadar vitamin C untuk sampel A adalah 1,244 mg/L. Pada sampel M memiliki kadar vitamin C sebesar 1,904 
$\mathrm{mg} / \mathrm{L}$. Merujuk pada data Tabel 3 terlihat jelas bahwa antara sampel A dan M memiliki kandungan vitamin $\mathrm{C}$ yang berbeda dimana pada daging buah markisa hutan (M) memiliki kandungan vitamin $C$ lebih banyak dibanding dengan buah ara (A). Hal ini terjadi karena dipengaruhi oleh komposisi senyawa metabolik primer dan sekunder serta tingkat kematangan (Rahmawati dkk., 2011).

Berdasarkan hasil penelitian ditemukan bahwa tingkat kematangan buah ara dan markisa hutan berbeda. Penampakan warna pada buah ara sangat merah dan orange. Sebaliknya buah markisa hutan tampak berwarna kuning kehijauan. Selain itu, daging buah markisa hutan memiliki cita rasa yang sedikit asam. Maka bertolak dari uraian tersebut dapat diasumsikan bahwa tingkat kematangan pada buah markisa hutan belum maksimal, faktor ini turut mempengaruhi kadar vitamin C. Perbedaan aspek ini mempertegas bahwa kadar vitamin $\mathrm{C}$ pada buah markisa hutan lebih banyak dibandingkan dengan buah ara. Rahmawati dkk. (2011) menjelaskan pula bahwa kadar vitamin C dipengaruhi oleh tingkat kematangan. Secara kasat mata buah ara yang telah matang tampak berwarna merah dan orange kondisi ini mengindikasikan buah ara lebih banyak mengandung senyawa karotenoid. Menurut Landrum (2009), buah dan sayuran yang berwarna kuning, orange, dan merah mengindikasikan adanya pigmen karotenoid dan sebuah capaian kematangan fisiologis. Pada periode ini, terjadi perubahan fisiologis dan morfologis termasuk warna kulit buah yang berwarna hijau (klorofil) menjadi merah (karotenoid) (Novita dkk., 2015).

Menurut Tando (2018), senyawa metabolik sekunder merupakan senyawa yang disintesis oleh sel tumbuhan. Sintesis senyawa ini dipengaruhi oleh tingkat pertumbuhan. Selama proses atau periode kematangan buah berlangsung terjadi perubahan biokimia yang mempengaruhi komposisi kimia buah dan sayuran seperti kandungan klorofil dan karotenoid. Semakin menigkat tingkat kematangan maka semakin menurun pula kandungan klorofil sebagai pigmen utama dan pigmen karotenoid sebagai pigmen asesoris akan terus meningkat. Perlu diketahui pula bahwa vitamin $\mathrm{C}$ akan menurun selama proses kematangan hal ini berkaitan dengan respirasi buah. Menurut Badriyah \& Manggara (2015), vitamin C memiliki sifat mudah teroksidasi karena merupakan salah satu turunan dari heksosa. Mekanisme inilah yang turut mempengaruhi kadar vitamin C pada buah ara dan markisa hutan. Dengan demikian tepat bahwa tingkat kematangan dan faktor biokimia masing-masing organisme (buah) turut mempengaruhi komposisi senyawa kimia yang terkandung termasuk vitamin C.

\section{KESIMPULAN}

Berdasarkan hasil analisis menunjukan bahwa pada daging buah ara (Ficus carica L.) dan markisa hutan (Passiflora foetida L.) mengandung vitamin C. Pengukuran kadar vitamin C pada daging buah ara dengan metode lodometri diperoleh 4,13 mg vitamin $C$ dan untuk buah markisa hutan diperoleh 5,16 mg vitamin C. Sedangkan untuk analisis secara spektrofotometri diperoleh kandungan Vitamin C pada buah ara sebesar 1,244 mg/L dan untuk buah markisa hutan diperoleh kandungan vitamin C sebesar 1,904 mg/L. Hasil ini juga mempertegas bahwa pada buah markisa hutan memiliki kandungan vitamin Clebih banyak dibanding dengan kandungan vitamin $\mathrm{C}$ pada buah ara. Perbedaan kadar vitamin $\mathrm{C}$ antara buah ara dan markisa hutan dipengaruhi oleh faktor metabolisme sekunder dan primer, tingkat kematangan, serta penyimpanan.

\section{SARAN}

Perlu dilakukan analisis lanjutan terkait uji bakteri dan uji antioksidan dari buah ara (Ficus carica L.) dan markisa hutan (Passiflora foetida L.).

\section{UCAPAN TERIMA KASIH}

Penulis mengucapkan terima kasih kepada Universitas Kristen Artha Wacana Kupang (LEMLIT) yang telah berkenan memberikan kesempatan dan pendanaan kepada penulis untuk melakukan analisis kadar vitamin C pada daging buah ara (Ficus carica L.) dan markisa hutan (Passiflora foetida L.). Penulis juga mengucapkan terima kasih kepada pengurus Laboratorium Eksakta Prodi Pendidikan Biologi UKAW dan pengurus Laboratorium IPA Terpadu Politani Negeri Kupang serta pihak-pihak yang telah membantu penulis dalam menyelesaikan penelitian. 


\section{DAFTAR PUSTAKA}

Aina, mia, \& Suprayogi, D. (2011). Uji Kualitatif Vitamin C Pada Berbagai Makanan Dan Pengaruhnya Terhadap Pemanasan. Jurnal Sains Dan Matematika, 3(1). https: //doi.org/ 10.1234/ sainmatika. v3i1.1615. P; 61-67

Badriyah, L., \& Manggara, A. B. (2015). Penetapan Kadar Vitamin C Pada Cabai Merah ( Capsicum annum L) Menggunakan Metode Spektrofotometri Uv- Vis. Jurnal Wiyata, 2(1), 25-28.

Damayanti, E. T., \& Kurniawati, P. (2017). Perbandingan Metode Penentuan Vitamin C Pada Minuman Kemasan Menggunakan Metode Spektrofotometer Uv-Vis Dan lodimetri. Prosiding Seminar Nasional Kimia Dan Pembelajarannya, (November), 258-266.

El-Ishaq, A., \& Obirinakem, S. (2015). Effect Of Temperature And Storage On Vitamin C Content In Fruits Juice. International Journal of Chemical and Biomolecular Science, 1(2), 17-21.

Karinda, M., \& Citraningtyas, G. (2013). Perbandingan Hasil Penetapan Kadar Vitamin C Mangga Dodol Dengan Menggunakan Metode Spektrofotometri Uv-Vis Dan Iodometri. Pharmacon Jurnal IImiah Farmasi - UNSRAT, 2(01), 2302-2493.

Landrum J.T. (2009). Carotenoids: Physical, chemical, and biological functions and properties (ISBN 1420052306) (562s).pdf.

Mulyani, E. (2018). Perbandingan Hasil Penetapan Kadar Vitamin C Pada Buah Kiwi (Actinidia deliciousa) Dengan Menggunakan Metode lodimetri Dan Spektrofotometri Uv-Vis. Jurnal Farmasi, Sains, Dan Kesehatan, 3(2), 14-17.

Novita, M., Satriana., Hamarita, E. (2015). Kandungan Likopen Dan Karotenoid Buah Tomat (Lycopersicum pyriforme) Pada Berbagai Tingkat Kematangan: Pengaruh Pelapisan Dengan Kitosan Dan Penyimpanan. Jurnal Teknologi dan Industri Pertanian Indonesia. 7(1), 35-39. https://doi.org/10.17969/jtipi.v7i1.2832

Rahmawati, I. S., Hastuti, E. D., \& Darmanti, S. (2011). Pengaruh Perlakuan Konsentrasi Kalsium $\left.\mathrm{Klorida} \mathrm{(CaCl}_{2}\right)$ Dan Lama Penyimpanan Terhadap Kadar Vitamin C Buah Tomat (Lycopersicum esculentum Mill). Jurnal Buletin Anatomi Dan Fisiologi, XIX(1), 62-70.

Setiawan, H., Mulyani, S., \& Made, I. (2014). Analisis Kandungan Vitamin C Dan Kalium Dalam Labu Kuning (Cucurbita moschata). Jurnal Akademika Kimia. 3(4) 173-177

Setyawati, T. (2014). Peran Vitamin V Pada Kulit. Jurnal Ilmiah Kedokteran, 1(2), 36-44

Tahir, M., Hikmah, N., \& Rahmawati, R. (2019). Analisis Kandungan Vitamin C Dan $\beta$-Karoten Dalam Daun Kelor (Moringa oleifra Lam) Dengan Metode Spektrofotometri Uv-Vis. Jurnal Fitofarmaka Indonesia, 3(1), 135-140. https://doi.org/10.33096/jffi.v3i1.173

Tando, E. (2018). Review : Potensi Senyawa Metabolit Sekunder Dalam Sirsak ( Annona murricata ) Dan Srikaya ( Annona squamosa) Sebagai Pestisida Nabati Untuk Pengendalian Hama Dan Penyakit Pada Tanaman. Jurnal Biotropika, 6(1), 21-27. 